\title{
DEA Game Cross-Efficiency Model to Urban Public Infrastructure Investment Comprehensive Efficiency of China
}

\author{
Yu Sun, ${ }^{1,2}$ Huixia Huang, ${ }^{1}$ and Chi Zhou ${ }^{3}$ \\ ${ }^{1}$ College of Management and Economics, Tianjin University, Tianjin 300072, China \\ ${ }^{2}$ School of Public Administration, Tianjin University of Commerce, Tianjin 300134, China \\ ${ }^{3}$ School of Management, Tianjin University of Technology, Tianjin 300384, China \\ Correspondence should be addressed to Huixia Huang; huanghuixia5@163.com
}

Received 29 July 2015; Accepted 18 February 2016

Academic Editor: Alessandro Gasparetto

Copyright (C) 2016 Yu Sun et al. This is an open access article distributed under the Creative Commons Attribution License, which permits unrestricted use, distribution, and reproduction in any medium, provided the original work is properly cited.

\begin{abstract}
In managerial application, data envelopment analysis (DEA) is used by numerous studies to evaluate performances and solve the allocation problem. As the problem of infrastructure investment becomes more and more important in Chinese cities, it is of vital necessity to evaluate the investment efficiency and assign the fund. In practice, there are competitions among cities due to the scarcity of investment funds. However, the traditional DEA model is a pure self-evaluation model without considering the impacts of the other decision-making units (DMUs). Even though using the cross-efficiency model can figure out the best multiplier bundle for the unit and other DMUs, the solution is not unique. Therefore, this paper introduces the game theory into DEA cross-efficiency model to evaluate the infrastructure investment efficiency when cities compete with each other. In this paper, we analyze the case involving 30 provincial capital cities of China. And the result shows that the approach can accomplish a unique and efficient solution for each city (DMU) after the investment fund is allocated as an input variable.
\end{abstract}

\section{Introduction}

China has experienced rapid urbanization since the reform and opening up process began in 1978 [1]. Along with the developmental speed, the national new urbanization planning (2014-2020) predicted that the urbanization rate of China will exceed 60\%, and it will exceed 60\%-70\% population living in cities by the end of 2020 . However, the urbanization causes numerous social and environmental problems and leads to a great pressure on constructing the resource-conserving and environment-friendly society. Therefore, it is of great importance for municipalities to improve the use efficiency of resources with full consideration of environmental condition.

Under that case, urban public infrastructure plays a fundamental and decisive role in urban development. In order to speed up urban development, each city has invested lots of fund in related public infrastructure. However, the World Bank estimated that the decision-making errors made by China in infrastructure investment were at about $30 \%$, which caused waste of about 400 billion to 500 billion RMB [2]. Hence, it is of vital significance to improve the investment efficiency.

The efficiency of urban public infrastructure investment has been a hot topic both in China and worldwide during the past decades. Morais et al. [3] analyzed the fiscal sustainability (FS) of an infrastructure investment project and believed that the infrastructure investment has a great influence on economic growth. Dahlgren and Leung [4] developed a framework for evaluating repeated infrastructure investments and used it to analyze the critical investment cost. Kemmerling and Stephan [5] studied the political institution in the regional allocation of public infrastructure investments in France, Germany, Italy, and Spain. Zheng et al. [6] examined determinants of regional allocation of infrastructure investment made by the central government and believed that the balance of equity and efficiency is important to the central government's decision-making. Pradeep and Nair [7] and Mishra et al. [8] studied the transport infrastructure 
investment. Since the investments are usually costly and irreversible, they believed that it is important to find a reliable and logical appraisal method to assign the investment.

Throughout the existing research, there is no doubt that investing in urban public infrastructure scientifically will benefit the comprehensive development. And to improve the urban infrastructure investment efficiency, it is necessary to establish a scheme. As the infrastructure investment efficiency is usually measured by comparing performance indicators where data envelopment analysis (DEA) $[9,10]$ performs very well, DEA has been widely used in recent literature to evaluate the relative urban infrastructure investment efficiency of different regions. For instance, Z.-F. Li and Y.-L. $\mathrm{Li}$ [11] regarded the DEA method as a nonparameter method to evaluate the performance of infrastructure investment in China. Yang and Gao [12] used the DEA model to evaluate the relative efficiency of city infrastructure investment of 10 cities in Shaanxi province from 2008 to 2013. Fancello et al. [13] used DEA to evaluate the urban road system. However, the conventional DEA model is a pure self-evaluation model and does not consider the impacts coming from other DMUs. Thus, the DEA cross-efficiency model was proposed [14, 15]. For example, Sun et al. [16] used DEA cross-efficiency model to evaluate and analyze the urban infrastructure economic efficiency of 35 Chinese large and medium-sized cities in 2012. However, the DEA cross-efficiency model also has limitations: the solution depends on the solving software and it is not unique; the average cross-efficiency is not Pareto solution. Therefore, Liang et al. [17] introduced the game theory into DEA cross-efficiency model. In existing literature, there are some researches discussing about efficiency evaluation with the DEA game cross-efficiency model. Yang et al. [18] proposed a DEA cross-efficiency method with both competition and corporation among DMUs, which considers a specific DMU's individual preference in differential treatment to other DMUs. Wu et al. [19] used the DEA game cross-efficiency to evaluate the Olympic games and ranked the countries participating in it. Ma et al. [20] used this method to assess supplier performance and then to obtain the Pareto solution. Ma et al. [21] developed a DEA game cross-efficiency with two-stage structures to evaluate the performance of top 30 US commercial banks and got a unique reasonable cross-efficiency for each DMU. In order to study the efficiency of infrastructure investment and the fund allocation of Chinese provincial capital cities, we treat the cities as DMUs. As there are competitions existing among the cities, it is rational to use the DEA game cross-efficiency model to evaluate the comprehensive efficiency of each city in urban public infrastructure and allocate funds.

The rest of this paper is organized as follows. Section 2 introduces the comprehensive efficiency of infrastructure investment, selects indexes about the comprehensive efficiency of public infrastructure investment, and then describes the DEA game cross-efficiency model. And the model analysis and the validation are presented in Section 3. Section 4 illustrates the results of the model and makes detailed discussion. In the end, Section 5 summarizes the main conclusions of the research.

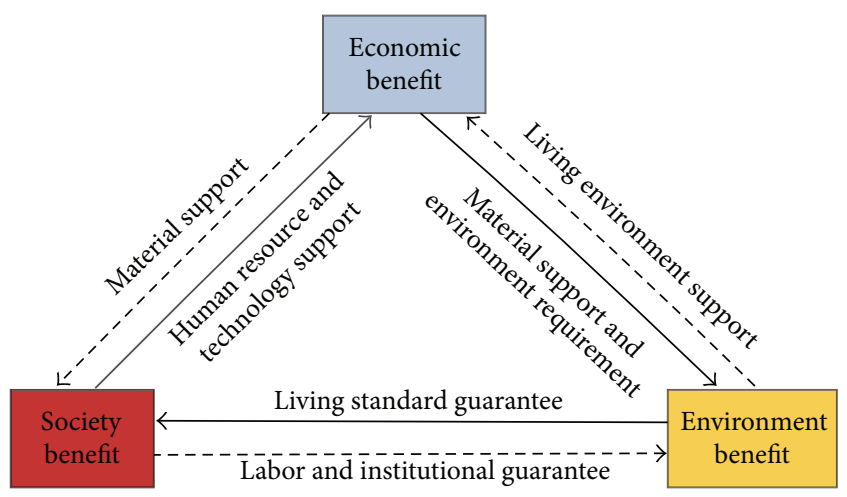

FIGURE 1: Synergies of benefits of public infrastructure investment.

\section{Game Cross-Efficiency for Public Infrastructure Investment}

2.1. Index Selection. Urban public infrastructure, which provides convenience for the city producing and living, includes transportation infrastructure, water infrastructure, energy infrastructure, ecological infrastructure, disaster-preventing infrastructure, and telecommunications infrastructure. In the long-term interactive relationship with economic development, investing in public infrastructure construction could promote the development of economy. Besides, it could improve employment rate, labor productivity, sociocultural integration level, and living environment quality and reduce the urban heat island effect while guaranteeing the residents' health. Generally, the comprehensive efficiency of urban infrastructure investment can be divided into economic efficiency, society efficiency, and environment efficiency, which influence, interact, and depend on each other. In order to improve the comprehensive efficiency of infrastructure investment, all these three dimensions should be coordinated and cooperated synergistically.

There is no doubt that increasing infrastructure investment could benefit the economy development of a city. Meanwhile, it could also provide channels for the improvement of urban society and environment. For the formation and development of society and environment, the economy provides material and basic supports. And the development of the society offers the human resource, technology, and policies to develop economy and improve environment. Mutually, a good urban living environment could speed up economy development and improve the living situations of residents. The synergies of public infrastructure investment benefits are shown in Figure 1.

The indexes of urban public infrastructure keep connection with each other, while possessing independence, respectively. Considering there are positive (preference value is bigger and better) and negative (preference value is smaller and better) factors that affect the assessment synthetically [22], in order to simplify calculation, we design the positive indexes for the comprehensive benefits. With consideration about most important elements of the investment purposes and data access, we use the following evaluation index system of urban infrastructure investment (seen in Table 1). 
TABLE 1: The index system of urban public infrastructure investment comprehensive benefit.

\begin{tabular}{|c|c|c|}
\hline Macroareas & Input & Output \\
\hline Economy & Completed investment (10,000 RMB) & $\begin{array}{l}\text { Revenue of urban maintenance and construction fund } \\
(10,000 \mathrm{RMB})\end{array}$ \\
\hline Society & $\begin{array}{l}\text { Water system investment }(10,000 \mathrm{RMB}) \\
\text { Energy system investment }(10,000 \mathrm{RMB}) \\
\text { Transportation system investment }(10,000 \mathrm{RMB})\end{array}$ & $\begin{array}{l}\text { Water supply (10,000 tons) } \\
\text { Gas supply (10,000 cubic meters) } \\
\text { Surface area of roads }\left(10,000 \mathrm{~m}^{2}\right) \\
\text { Person employed ( } 10,000 \text { persons) } \\
\text { Collection of public libraries per } 100 \text { persons (copy, piece) }\end{array}$ \\
\hline Environment & Environmental system investment (10,000 RMB) & Green coverage area-built district (hectare) \\
\hline
\end{tabular}

2.2. DEA Game Cross-Efficiency Model. For allocating the fund scientifically and reasonably, the DEA game crossefficiency model is adapted to evaluate the comprehensive efficiency of urban infrastructure investment. Assume that there were $n$ cities with $m$ inputs and $s$ outputs. For the city $j, x_{i j}(i=1,2, \ldots, m)$ represents $i$ th input and $y_{r j}(r=$ $1,2, \ldots, s)$ represents $r$ th output. Suppose that the total capital $C$ would be distributed among all cities. The fund $c_{j}(j=$ $1,2, \ldots, n)$ is allocated to the city $j$ and $\sum_{j=1}^{n} c_{j}=C$. In the model, the fund $c_{j}$ is regarded as a new input variable [23], and then the efficiency score of the whole system for the city $d$ can be calculated with the modified CCR model as follows:

$$
\begin{array}{ll}
\max & \frac{\sum_{r=1}^{s} u_{r}^{d} y_{r d}}{\sum_{i=1}^{m} v_{i}^{d} x_{i d}+v_{m+1}^{d} c_{d}^{d}}=\theta_{d} \\
\text { s.t. } & \frac{\sum_{r=1}^{s} u_{r}^{d} y_{r j}}{\sum_{i=1}^{m} v_{i}^{d} x_{i j}+v_{m+1}^{d} c_{j}^{d}} \leq 1, \quad j=1,2, \ldots, n, \\
& \sum_{j=1}^{n} c_{j}^{d}=C, \\
& c_{j}^{d} \geq 0, \quad j=1,2, \ldots, n, \\
& v_{i}^{d} \geq 0, \quad i=1,2, \ldots, m, \\
& u_{r}^{d} \geq 0, \quad r=1,2, \ldots, s .
\end{array}
$$

In order to simplify calculation, we use Charnes-Cooper's method to transform model (1), and set $\omega_{m+1}^{d} c_{j}^{d}$ as a new variable $\widehat{c}_{j}^{d}$, and then get a LP model:

$$
\begin{aligned}
\max & \sum_{r=1}^{s} \mu_{r}^{d} y_{r d}=\theta_{d} \\
\text { s.t. } & \sum_{i=1}^{m} \omega_{i}^{d} x_{i j}+\widehat{c}_{j}^{d}-\sum_{r=1}^{s} \mu_{r}^{d} y_{i j} \geq 0, \quad j=1,2, \ldots, n, \\
& \sum_{i=1}^{m} \omega_{i}^{d} x_{i d}+\widehat{c}_{d}^{d}=1,
\end{aligned}
$$

$$
\begin{aligned}
& \sum_{j=1}^{n} \widehat{c}_{j}^{d}=\omega_{m+1}^{d} C, \\
& \widehat{c}_{j}^{d} \geq 0, \quad j=1,2, \ldots, n, \\
& \omega_{i}^{d} \geq 0, \quad i=1,2, \ldots, m+1, \\
& \mu_{r}^{d} \geq 0, \quad r=1,2, \ldots, s .
\end{aligned}
$$

For each city $d$ under evaluation, we obtain a set of weight $\widehat{c}_{j}^{d^{*}}(j=1,2, \ldots, n), \omega_{i}^{d^{*}}(i=1,2, \ldots, m+1), \mu_{r}^{d^{*}}(r=$ $1,2, \ldots, s)$. Using this set of weights, the $d$-cross-efficiency for any city $j$ can be calculated as

$$
E_{d j}=\frac{\sum_{r=1}^{s} \mu_{r}^{d^{*}} y_{r j}}{\sum_{i=1}^{m} \omega_{i}^{d^{*}} x_{i j}+\widehat{c}_{j}^{d^{*}}}, \quad d, j=1,2, \ldots, n .
$$

For each city $j$, the average of all of the $d$-cross-efficiency is as follows:

$$
\bar{E}_{j}=\frac{1}{n} \sum_{d=1}^{n} E_{d j} .
$$

However, the cross-efficiency is not unique here, and it yields nonunique allocation plans. According to Liang et al. [17] and Cheng et al. [24], we regard the cities as DMUs and assume that they are players of noncooperative game. Cities compete with each other. Suppose that, in the sense of noncooperative game, a player $\mathrm{DMU}_{d}$ gets an efficiency score $\alpha_{d}$ which cannot be decreased when another player $\mathrm{DMU}_{j}$ tries to maximize its own efficiency. Then the game $d$-crossefficiency of overall system for $\mathrm{DMU}_{j}$ relative to $\mathrm{DMU}_{d}$ is defined as

$$
\alpha_{d j}=\frac{\sum_{r=1}^{s} \mu_{r}^{d} y_{r j}}{\sum_{i=1}^{m} \omega_{i}^{d} x_{i j}+\widehat{c}_{j}^{d}}, \quad d, j=1,2, \ldots, n,
$$


where $\mu_{r}^{d}(r=1,2, \ldots, s), \omega_{i}^{d}(i=1,2, \ldots, m+1)$, and $\widehat{c}_{j}^{d}(j=$ $1,2, \ldots, n)$ are the optimal solutions of the following game $d$ cross-efficiency model:

$$
\begin{array}{ll}
\max & \sum_{r=1}^{s} \mu_{r}^{d} y_{r d}=\theta_{d} \\
\text { s.t. } & \sum_{i=1}^{m} \omega_{i}^{d} x_{i j}+\widehat{c}_{j}^{d}-\sum_{r=1}^{s} \mu_{r}^{d} y_{i j} \geq 0, \quad j=1,2, \ldots, n, \\
& \alpha_{d} \times\left(\sum_{i=1}^{m} \omega_{i}^{d} x_{i d}+\widehat{c}_{d}^{d}\right)-\sum_{r=1}^{s} \mu_{r}^{d} y_{i d} \leq 0, \\
& \sum_{i=1}^{m} \omega_{i d} x_{i d}+\widehat{c}_{d}^{d}=1, \\
& \sum_{j=1}^{n} \widehat{c}_{j}^{d}=\omega_{m+1}^{d} C, \\
& \widehat{c}_{j}^{d} \geq 0, \quad j=1,2, \ldots, n, \\
& \omega_{i}^{d} \geq 0, \quad i=1,2, \ldots, m+1, \\
& \mu_{r}^{d} \geq 0, \quad r=1,2, \ldots, s,
\end{array}
$$

where the parameter $\alpha_{d} \leq 1$.

According to the above analysis, we propose the following iterative algorithm, which begins with solving model (2) and then obtains an original cross-efficiency score defined in (4). And that process would be repeated for every $d$, and the optimal value of model (6) comes as a revised $\alpha_{d}$. Assuming $\mu_{r}^{d^{*}}\left(\alpha_{d}\right)$ was an optimal solution to model (6), for each $\mathrm{DMU}_{j}, \alpha_{j}=(1 / n) \sum_{d=1}^{n} \sum_{r=1}^{s} \mu_{r}^{d^{*}}\left(\alpha_{d}\right) y_{r j}$ is called the average game cross-efficiency. Through circular computations, the algorithm terminates until $\alpha_{j}$ converges to a stable value.

\section{Algorithm 1.}

Step 1. Solve the traditional DEA game cross-efficiency model and obtain a set of initial cross-efficiency scores defined in (4). Let $t=1$ and $\alpha_{d}=\alpha_{d}^{1}=\bar{E}_{d}$.

Step 2. Solve model (6) with $\alpha_{d}=\alpha_{d}^{1}$; let $\alpha_{j}^{2}=$ $(1 / n) \sum_{d=1}^{n} \sum_{r=1}^{s} \mu_{r}^{d^{*}}\left(\alpha_{d}^{1}\right) y_{r j}(j=1,2, \ldots, n)$. The general form is calculated as $\alpha_{j}^{t+1}=(1 / n) \sum_{d=1}^{n} \sum_{r=1}^{s} \mu_{r}^{d^{*}}\left(\alpha_{d}^{t}\right) y_{r j}(j=$ $1,2, \ldots, n)$.

Step 3. If $\left|\alpha_{j}^{t+1}-\alpha_{j}^{t}\right| \geq \varepsilon$ (where $\varepsilon$ is a given small positive value) for some $j$, set $\alpha_{d}=\alpha_{d}^{t+1}$ and go back to Step 2; otherwise, stop the iteration and $\alpha_{j}^{t+1}$ is the best solution of the system.

\section{Model Analysis and Validation}

3.1. Data. In this section, we select 30 Chinese cities for evaluation and ranking, including 1 national capital city (i.e., Beijing), 3 direct-controlled municipalities (i.e., Tianjin,
Shanghai, and Chongqing), and 26 provincial capital cities. Without loss of generality, Lhasa, Hong Kong, Macao, and Taiwan are not included in the analysis due to the lack of statistical data. In this paper, the data is derived from the China City Statistical Yearbook 2013 (which covers the main socioeconomic statistical data for 2012), which is compiled by the Department of Urban Society and Economic Statistics, National Bureau of Statistics of China, and the 2012 China Urban Construction Statistical Yearbook (which covers the statistical data on urban construction in 2012), which is compiled by Ministry of Housing and Urban-Rural Development, China.

According to the statistical yearbook and the input indexes of Table 1, we organize the original data which is shown in Table 2. Table 2 indicates that the water system investment includes the investment of water supply and sewerage, and the energy system investment is made up of gas supply investment and central heating investment. And the transportation system investment is composed of urban rail transit system investment and road and bridge investment. In addition, the environment system investment consists of landscaping investment and environmental sanitation investment. Similarity, depending on the output indexes of Table 1, the original data is shown in Table 3.

Then, we apply the DEA game cross-efficiency model to analyze the performance of urban infrastructure investment and apply a scientific method to allocate the fund of investment reasonably. We use MATLAB 7.0 to calculate the comprehensive efficiencies of infrastructure investment for the chosen cities. In the algorithm, we use the traditional DEA cross-efficiency as $\alpha_{d}^{1}$ and set $\varepsilon=0.0001$. Considering the cross-efficiency is not unique, we impose the secondary goals and propose three alternative methods. The first method is the aggressive strategy, which maximizes DEA efficiency for a DMU as the primary goal and minimizes the other DMUs' cross-efficiencies as a secondary goal [14]. The second method is the benevolent strategy, which maximizes the cross-efficiencies of other DMUs' as a secondary goal [15]. The third method is the arbitrary strategy, which does not impose the secondary goal. However, no matter which method is chosen, the DEA game cross-efficiency should converge to a solution no matter which method is chosen [19]. Therefore, we adopt the aggressive strategy as the original value, and the corresponding results of DEA game cross-efficiency are shown in Table 4.

3.2. Model Validation. By solving the DEA game crossefficiency model, it is obvious that the game cross-efficiency is connected with the input and output indexes of urban public infrastructure. In order to test the credibility of the results, we need to establish the relationship between the results and the indexes. Considering various facts of situations, the multiple linear regression method is used to test the model. We regard the game cross-efficiency as dependent variables and take the input and output indexes of urban public infrastructure as independent variables.

The multiple linear regression model is as follows:

$$
y=\beta_{0}+\beta_{1} x_{1}+\cdots+\beta_{12} x_{12}+\varepsilon,
$$


TABLE 2: The urban infrastructure construction statistic data of input indexes in 2012.

\begin{tabular}{|c|c|c|c|c|c|c|}
\hline DMU & Cities & $\begin{array}{l}\text { Completed } \\
\text { investment }\end{array}$ & $\begin{array}{c}\text { Water system } \\
\text { investment }\end{array}$ & $\begin{array}{l}\text { Energy system } \\
\text { investment }\end{array}$ & $\begin{array}{c}\text { Transportation } \\
\text { system } \\
\text { investment }\end{array}$ & $\begin{array}{c}\text { Environmental } \\
\text { system } \\
\text { investment }\end{array}$ \\
\hline 1 & Beijing & 12162405 & 600802 & 944859 & 7208204 & 1783322 \\
\hline 2 & Tianjin & 6540958 & 136451 & 218055 & 3965879 & 667863 \\
\hline 3 & Shijiazhuang & 1030696 & 115700 & 86600 & 655508 & 743435 \\
\hline 4 & Taiyuan & 1209732 & 17600 & 766330 & 239136 & 111656 \\
\hline 5 & Hohhot & 923993 & 83653 & 77033 & 536149 & 227158 \\
\hline 6 & Shenyang & 4966546 & 493390 & 286049 & 3273487 & 820659 \\
\hline 7 & Changchun & 1917746 & 75284 & 89164 & 1537984 & 57744 \\
\hline 8 & Harbin & 2058076 & 1160 & 108703 & 1226271 & 159573 \\
\hline 9 & Shanghai & 3393269 & 425108 & 138720 & 2375115 & 342831 \\
\hline 10 & Nanjing & 3999657 & 375792 & 60437 & 3270255 & 270516 \\
\hline 11 & Hangzhou & 1440705 & 41717 & 45569 & 1278534 & 65404 \\
\hline 12 & Hefei & 810014 & 43640 & 25542 & 591975 & 127896 \\
\hline 13 & Fuzhou & 1070667 & 56826 & 7083 & 847390 & 134051 \\
\hline 14 & Nanchang & 2761493 & 57901 & 121947 & 1933313 & 364760 \\
\hline 15 & Jinan & 1003467 & 130111 & 148154 & 558054 & 45901 \\
\hline 16 & Zhengzhou & 1079420 & 51766 & 51359 & 865713 & 110582 \\
\hline 17 & Wuhan & 6645218 & 786184 & - & 5140003 & 524932 \\
\hline 18 & Changsha & 1679690 & 58059 & 9200 & 935186 & 232585 \\
\hline 19 & Guangzhou & 2022147 & 124400 & 29378 & 1552371 & 75824 \\
\hline 20 & Nanning & 757615 & 28779 & 8305 & 646653 & 73860 \\
\hline 21 & Haikou & 474786 & 111782 & - & 288898 & 74106 \\
\hline 22 & Chongqing & 4607586 & 273448 & 26200 & 3565109 & 680812 \\
\hline 23 & Chengdu & 3934694 & 66407 & 5189 & 3761150 & 17896 \\
\hline 24 & Guiyang & 789180 & 20595 & 12091 & 755616 & 878 \\
\hline 25 & Kunming & 538755 & 71982 & - & 419849 & 45291 \\
\hline 26 & Xi'an & 2477694 & 44173 & 33591 & 1391493 & 172742 \\
\hline 27 & Lanzhou & 1472719 & 35963 & 11093 & 1208824 & 198611 \\
\hline 28 & Xining & 388893 & 13800 & 19116 & 280303 & - \\
\hline 29 & Yinchuan & 127955 & 3901 & 28266 & 66723 & - \\
\hline 30 & Urumqi & 2269254 & 41600 & 614472 & 479445 & - \\
\hline
\end{tabular}

Note: "-" means the missing data.

where $y$ is the game cross-efficiency of the public infrastructure investment, which is shown in column 5 of Table 4 . And $x_{i}(i=1,2, \ldots, 5)$ is the input index of urban public infrastructure, which is shown in Table $2 ; x_{i}(i=6,7, \ldots, 12)$ is the output index of urban public infrastructure, which is shown in Table 3.

The multiple linear regression model is employed by using SPSS, and the test results are shown in Tables 5 and 6. It can be seen that the results show a high consistency. For example, the $R$ achieves 0.909 , the $R$ square achieves 0.826 , and the adjusted $R$ square achieves 0.704 . In addition, the Analysis of Variance (ANOVA) shows that the $P$ value is 0.000: that is to say, the DEA game cross-efficiency model passes the significance testing. Hence, the results show that the DEA game cross-efficiency model is valid in the problem of evaluating the infrastructure investment efficiency.

\section{Results and Discussions}

In this section, we apply the DEA game cross-efficiency model presented in the previous sections to analyze the efficiency and the assignment weight of the urban public infrastructure investment.

The game cross-efficiency and its ranking can be seen in column 5 and column 6 of Table 4 . It shows that the top ten cities are mainly from west region, and the bottom ten cities are mainly from east region. However, it is the east region that mainly controls the assignment weight. One possible reason for that could be that the cities in east region are economically advanced ones needing urban infrastructure of high level. Nevertheless, these cities have high population density and serious environmental pollution, which causes difficulties in improving the performance of economy, society, and 
TABLE 3: The urban infrastructure construction statistic data of output indexes in 2012.

\begin{tabular}{|c|c|c|c|c|c|c|c|c|}
\hline DMU & Cities & $\begin{array}{l}\text { Revenue of urban } \\
\text { maintenance } \\
\text { and construction } \\
\text { fund }\end{array}$ & $\begin{array}{l}\text { Water } \\
\text { supply }\end{array}$ & $\begin{array}{l}\text { Gas } \\
\text { supply }\end{array}$ & $\begin{array}{c}\text { Surface area } \\
\text { of roads }\end{array}$ & $\begin{array}{c}\text { Person } \\
\text { employed }\end{array}$ & $\begin{array}{l}\text { Collection of } \\
\text { public } \\
\text { libraries per } 100 \\
\text { persons } \\
\end{array}$ & $\begin{array}{c}\text { Green coverage } \\
\text { area-built } \\
\text { district }\end{array}$ \\
\hline 1 & Beijing & 18436572 & 159646 & 924763 & 13509 & 118.89 & 445.5 & 68204 \\
\hline 2 & Tianjin & 1687948 & 77218 & 256241 & 11611 & 53.23 & 176.27 & 25191 \\
\hline 3 & Shijiazhuang & 623340 & 33531 & 24613 & 4285 & 19.49 & 180.46 & 8868 \\
\hline 4 & Taiyuan & 766172 & 31107 & 106822 & 2904 & 33.19 & 171.61 & 12112 \\
\hline 5 & Hohhot & 218142 & 13718 & 42050 & 1949 & 7.29 & 174.66 & 7798 \\
\hline 6 & Shenyang & 1666059 & 56641 & 43332 & 6647 & 25.34 & 242.05 & 19210 \\
\hline 7 & Changchun & 761351 & 34951 & 44615 & 6457 & 17.84 & 244.23 & 15220 \\
\hline 8 & Harbin & 583346 & 38653 & 33323 & 4624 & 34.45 & 162.25 & 14181 \\
\hline 9 & Shanghai & 2372764 & 309704 & 721564 & 9717 & 98.82 & 525.75 & 38242 \\
\hline 10 & Nanjing & 2081571 & 121401 & 82413 & 11424 & 27.93 & 274.37 & 28756 \\
\hline 11 & Hangzhou & 1427371 & 58182 & 55623 & 5284 & 96.24 & 351.53 & 18135 \\
\hline 12 & Hefei & 830742 & 34573 & 32924 & 4854 & 42.96 & 288.47 & 15088 \\
\hline 13 & Fuzhou & 978086 & 30166 & 13608 & 2563 & 50.55 & 76.17 & 9750 \\
\hline 14 & Nanchang & 318475 & 39397 & 20213 & 2391 & 34.7 & 230.55 & 9245 \\
\hline 15 & Jinan & 996423 & 33250 & 39300 & 7251 & 43.99 & 296.96 & 13803 \\
\hline 16 & Zhengzhou & 1189035 & 35824 & 75742 & 3564 & 35.75 & 82.56 & 13456 \\
\hline 17 & Wuhan & 475834 & 121552 & 125131 & 9027 & 64.9 & 2187.39 & 19870 \\
\hline 18 & Changsha & 617456 & 41997 & 64298 & 3958 & 26.55 & 319.23 & 10729 \\
\hline 19 & Guangzhou & 2191312 & 191432 & - & 10140 & 57.89 & 39.97 & 40895 \\
\hline 20 & Nanning & 1524615 & 40215 & 6554 & 3334 & 19.39 & 168.46 & 10165 \\
\hline 21 & Haikou & 104762 & 19066 & 12143 & 2439 & 8.6 & 42.94 & 5191 \\
\hline 22 & Chongqing & 3623844 & 95903 & 324965 & 11936 & 206.39 & 7.34 & 45157 \\
\hline 23 & Chengdu & 1632416 & 76021 & 210902 & 7441 & 64.47 & 165.05 & 20301 \\
\hline 24 & Guiyang & 133750 & 32855 & 26909 & 1348 & 29.05 & 98.82 & 22766 \\
\hline 25 & Kunming & 2091018 & 21984 & 30866 & 4056 & 39.63 & 35.47 & 16884 \\
\hline 26 & Xian & 2170117 & 43848 & 138050 & 6333 & 38.72 & 71.62 & 15750 \\
\hline 27 & Lanzhou & 369607 & 25035 & 88493 & 2219 & 14.88 & 288.95 & 5963 \\
\hline 28 & Xining & 215088 & 14633 & 102749 & 823 & 10.33 & 208.84 & 2812 \\
\hline 29 & Yinchuan & 146256 & 11468 & 147354 & 1809 & 7.96 & 45.6 & 5632 \\
\hline 30 & Urumqi & 707983 & 30363 & 146244 & 2225 & 11.8 & 123.55 & 13630 \\
\hline
\end{tabular}

Note: “-” means the missing data.

environment simultaneously. Under this case, one of the options to improve the comprehensive efficiency is to increase investment. Comparing with the cities in east region, the cities of the west region have lower population density, and less investment could keep high comprehensive efficiency. As a result, the investment ratio is relatively low while the overall efficiency value of input-output is higher than the east cities.

From column 6 in Table 4, Yinchuan is more efficient than other cities. However, it should be noted that Yinchuan is in the underdeveloped west area. Although its input value is small, the output value is relatively large, and then the game cross-efficiency scores are better than the other cities. According to the third column of Table 4, the allocation weight of infrastructure investment of Chongqing takes the largest proportion, followed by Beijing, Hangzhou, and Shanghai.

According to regional economic situation, the Chinese cities can be divided into four parts. The first part is the east region, including Beijing, Tianjin, Shijiazhuang, Shanghai, Nanjing, Hangzhou, Fuzhou, Jinan, Guangzhou, and Haikou. The second part is the central region, including Taiyuan, Hefei, Nanchang, Zhengzhou, Wuhan, and Changsha. The third part is the west region, including Hohhot, Nanning, Chongqing, Chengdu, Guiyang, Kunming, Xi’an, Lanzhou, Yinchuan, Xining, and Urumqi. The fourth part includes three provinces in the northeast of China, that is, Shenyang, Changchun, and Harbin.

This paper analyzes the convergence program of game cross-efficiency. For plotting convenience, we divide the east 
TABLE 4: Allocation results and game cross-efficiency for cities in 2012.

\begin{tabular}{|c|c|c|c|c|c|}
\hline DMU & Cities & Assignment weight & Ranking & Game cross-efficiency & Ranking \\
\hline 1 & Beijing & 0.0794 & 2 & 0.9990 & 23 \\
\hline 2 & Tianjin & 0.0393 & 8 & 0.9990 & 22 \\
\hline 3 & Shijiazhuang & 0.0141 & 22 & 0.9991 & 21 \\
\hline 4 & Taiyuan & 0.0243 & 17 & 0.9989 & 24 \\
\hline 5 & Hohhot & 0.0047 & 30 & 0.9985 & 26 \\
\hline 6 & Shenyang & 0.0118 & 24 & 0.9964 & 30 \\
\hline 7 & Changchun & 0.0135 & 23 & 0.9995 & 19 \\
\hline 8 & Harbin & 0.0273 & 14 & 0.9997 & 17 \\
\hline 9 & Shanghai & 0.0760 & 4 & 0.9997 & 12 \\
\hline 10 & Nanjing & 0.0180 & 20 & 0.9995 & 20 \\
\hline 11 & Hangzhou & 0.0761 & 3 & 0.9999 & 5 \\
\hline 12 & Hefei & 0.0343 & 11 & 0.9999 & 4 \\
\hline 13 & Fuzhou & 0.0388 & 9 & 0.9998 & 10 \\
\hline 14 & Nanchang & 0.0250 & 16 & 0.9974 & 28 \\
\hline 15 & Jinan & 0.0345 & 10 & 0.9997 & 14 \\
\hline 16 & Zhengzhou & 0.0273 & 15 & 0.9997 & 13 \\
\hline 17 & Wuhan & 0.0422 & 7 & 0.9985 & 27 \\
\hline 18 & Changsha & 0.0207 & 19 & 0.9998 & 8 \\
\hline 19 & Guangzhou & 0.0467 & 6 & 0.9999 & 3 \\
\hline 20 & Nanning & 0.0144 & 21 & 0.9997 & 15 \\
\hline 21 & Haikou & 0.0059 & 29 & 0.9989 & 25 \\
\hline 22 & Chongqing & 0.1594 & 1 & 0.9998 & 9 \\
\hline 23 & Chengdu & 0.0488 & 5 & 0.9999 & 6 \\
\hline 24 & Guiyang & 0.0231 & 18 & 0.9998 & 7 \\
\hline 25 & Kunming & 0.0295 & 13 & 0.9997 & 16 \\
\hline 26 & Xi'an & 0.0320 & 12 & 0.9999 & 2 \\
\hline 27 & Lanzhou & 0.0110 & 25 & 0.9996 & 18 \\
\hline 28 & Xining & 0.0081 & 26 & 0.9997 & 11 \\
\hline 29 & Yinchuan & 0.0069 & 28 & 0.9999 & 1 \\
\hline 30 & Urumqi & 0.0071 & 27 & 0.9964 & 29 \\
\hline
\end{tabular}

TABLE 5: The summary of multiple linear regression model.

\begin{tabular}{|c|c|c|c|c|}
\hline Model & $R$ & $R$ square & $\begin{array}{l}\text { Adjusted } \\
R \text { square }\end{array}$ & $\begin{array}{l}\text { Std. error of } \\
\text { the estimate }\end{array}$ \\
\hline 1 & $.909^{\mathrm{a}}$ & .826 & .704 & .00052 \\
\hline
\end{tabular}

TABLE 6: The ANOVA ${ }^{\mathrm{b}}$ of multiple linear regression model.

\begin{tabular}{|c|c|c|c|c|c|c|}
\hline & Model & Sum of squares & $\mathrm{df}$ & Mean square & $F$ & Sig. \\
\hline \multirow{3}{*}{1} & Regression & .000 & 12 & .000 & 6.741 & $.000^{\mathrm{a}}$ \\
\hline & Residual & .000 & 17 & .000 & & \\
\hline & Total & .000 & 29 & & & \\
\hline
\end{tabular}

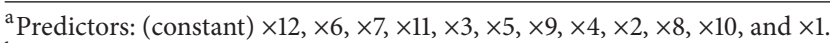

${ }^{\mathrm{b}}$ Dependent variable: $y$.

region cities and the west region cities into two parts and draw iterated graphs, respectively (seen in Figures 2-7). With further comparison, it shows that the iterative curves of most cities in west region are better than the rest of the cities. However, the differences between cities are obviously large. Figures 4 and 5 show that the comprehensive efficiency of Urumqi and that of Hohhot are worse than others in every iteration, and the comprehensive efficiency of Xi'an and that of Yinchuan are better than other cities. The iterative processes of east region cities (seen in Figures 2 and 3) 


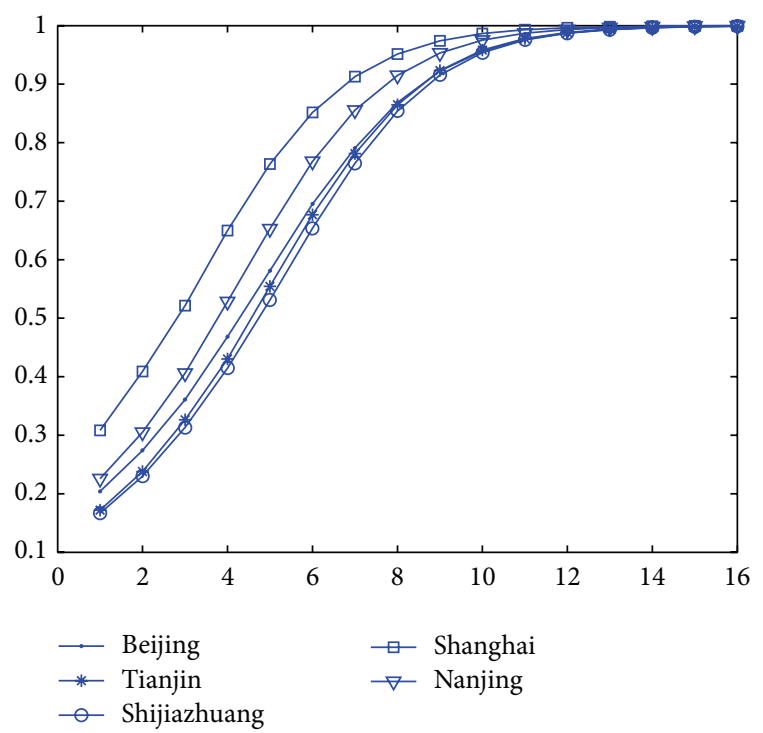

FIGURE 2: Game cross-efficiency calculation for the east region cities.

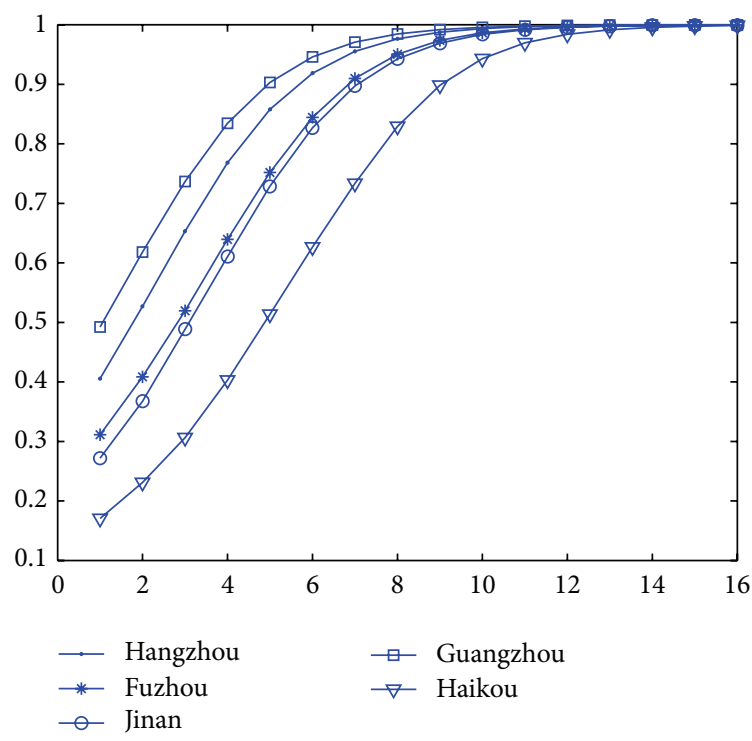

FIGURE 3: Game cross-efficiency calculation for the east region cities.

are relatively more centralized. Figures 6 and 7 show the iteration of central region cities and the three provinces in the northeast of China, respectively. It shows that even though there is not a big gap, the average iterative process is worse. The iteration diagrams indicate the imbalanced circumstance of urban infrastructure investment in China. In order to construct the urbanization better, the national government should invest reasonably in cities according to the complexity of the cities.

\section{Conclusions}

In this paper, we use a DEA game cross-efficiency model to evaluate the urban infrastructure investment efficiency and

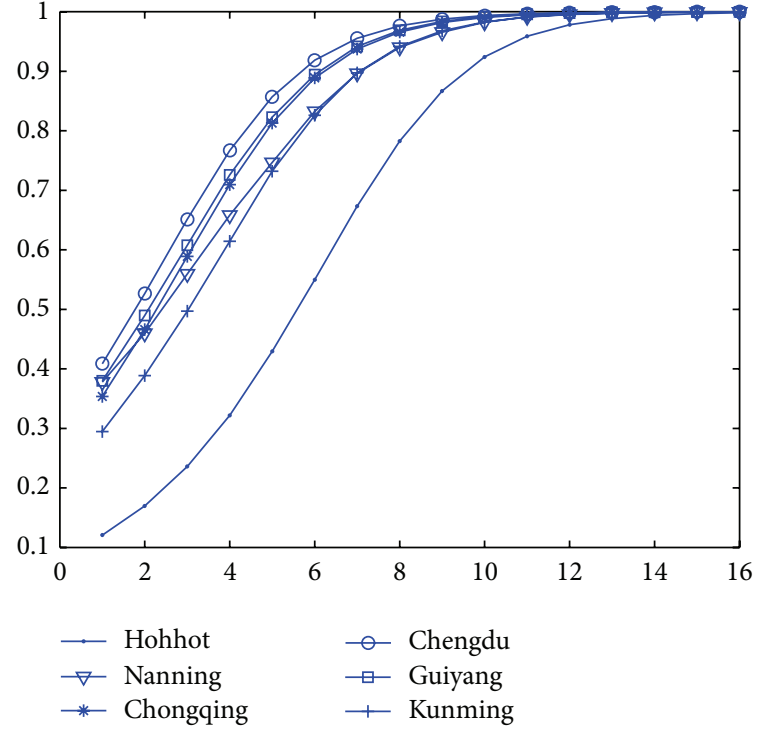

Figure 4: Game cross-efficiency calculation for the west region cities.

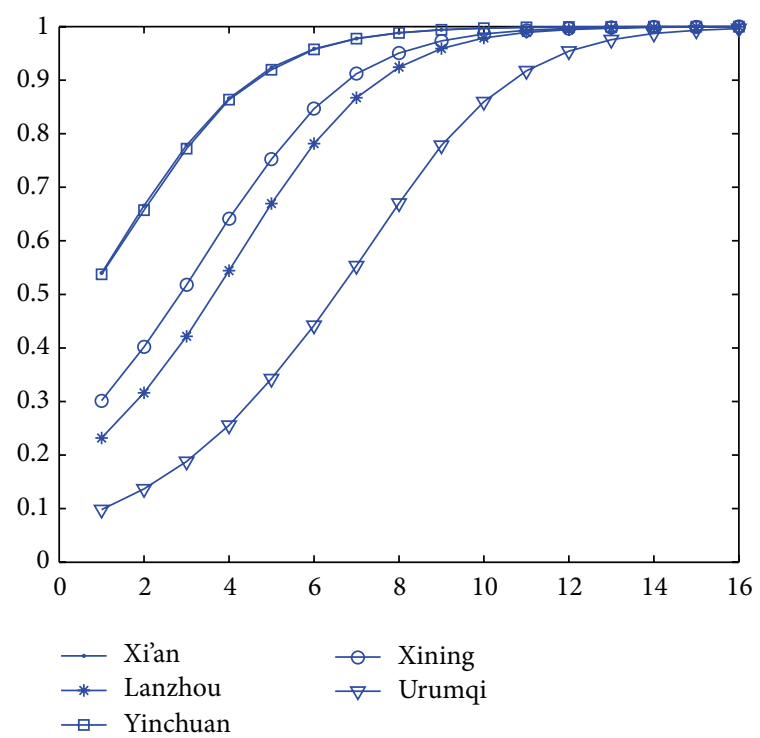

FIGURE 5: Game cross-efficiency calculation for the west region cities.

find a scientific method to distribute the fund. We figure out a Nash equilibrium point and solve the nonunique problem. The final scores from the DEA game cross-efficiency show that the investment from different infrastructure subsystems is related to many factors influencing the economic, society, and environment developments.

Though we have concentrated on the DEA game crossefficiency model widely used in efficiency evaluation and fund allocation, there are limitations of our analysis when the comprehensive efficiency is supposed to include economy, society, and environment. A city has its own complex infrastructure system that is different from others, but this paper 


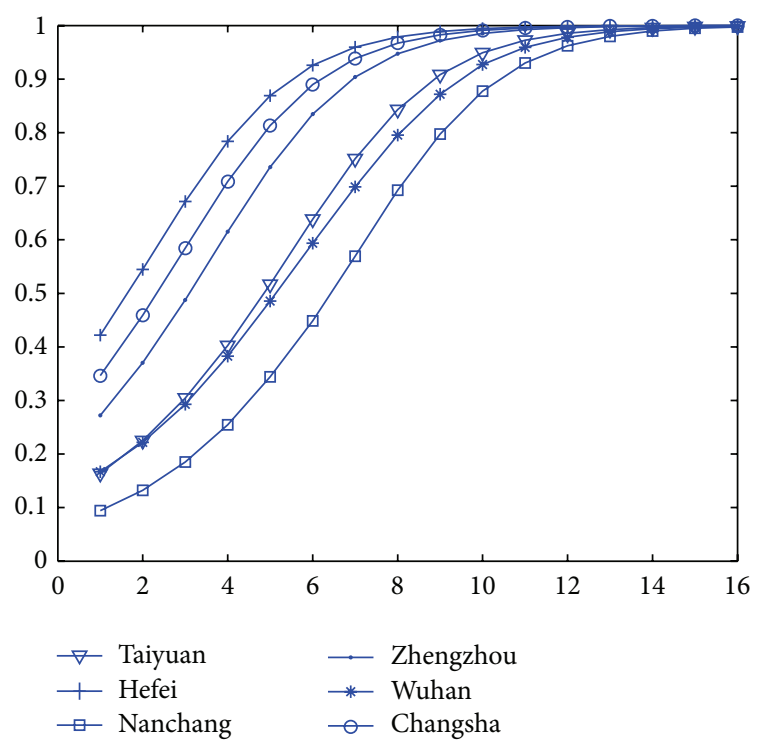

FIGURE 6: Game cross-efficiency calculation for the central region cities.

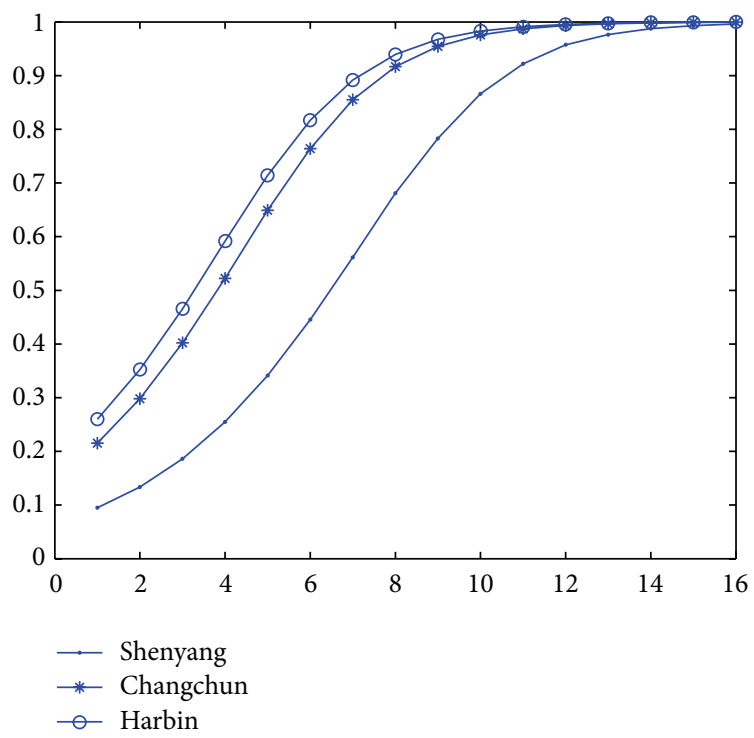

FIgURE 7: Game cross-efficiency calculation for Shenyang, Changchun, and Harbin.

only provides a relative evaluation of the 30 cities in terms of their investment amount. Future researches could establish nonquantitative DEA game cross-efficiency model to explain the relationship between the efficiency and the infrastructure subsystems.

\section{Conflict of Interests}

The authors declare that there is no conflict of interests regarding the publication of this paper.

\section{Acknowledgment}

The research was supported by the National Natural Science Fund Project in 2012, Project approval no. 71273186, research period: 2012-2016.

\section{References}

[1] X. Zhang, Y. Li, and W. Wu, "Evaluation of urban resource and environmental efficiency in China based on the DEA model," Journal of Resources and Ecology, vol. 5, no. 1, pp. 11-19, 2014.

[2] V. Henderson, "Urbanization in developing countries," The World Bank Research Observer, vol. 17, no. 1, pp. 89-112, 2002.

[3] A. C. Morais, J. J. G. Aragão, Y. Yamashita, R. D. Orrico, and A. B. de Freitas Dourado, "Analysing the fiscal sustainability of transit investment projects: the case of the metropolitan railway of Brasília," Research in Transportation Economics, vol. 48, pp. 422-428, 2014.

[4] E. Dahlgren and T. Leung, "An optimal multiple stopping approach to infrastructure investment decisions," Journal of Economic Dynamics \& Control, vol. 53, pp. 251-267, 2015.

[5] A. Kemmerling and A. Stephan, "Comparative political economy of regional transport infrastructure investment in Europe," Journal of Comparative Economics, vol. 43, no. 1, pp. 227-239, 2015.

[6] X. Zheng, F. Li, S. Song, and Y. Yu, "Central government's infrastructure investment across Chinese regions: a dynamic spatial panel data approach," China Economic Review, vol. 27, pp. 264-276, 2013.

[7] J. Pradeep and V. C. Nair, "A scientific approach to prioritizing highway infrastructure investment schemes," Procedia-Social and Behavioral Sciences, vol. 104, pp. 932-941, 2013.

[8] S. Mishra, S. Khasnabis, and S. Swain, "Multi-entity perspective transportation infrastructure investment decision making," Transport Policy, vol. 30, pp. 1-12, 2013.

[9] X. Han, X. Xue, J. Ge, H. Wu, and C. Su, "Measuring the productivity of energy consumption of major industries in China: a DEA-based method," Mathematical Problems in Engineering, vol. 2014, Article ID 121804, 12 pages, 2014.

[10] J. Huang, J. Chen, and Z. Yin, "A network DEA model with super efficiency and undesirable outputs: an application to bank efficiency in China," Mathematical Problems in Engineering, vol. 2014, Article ID 793192, 14 pages, 2014.

[11] Z.-F. Li and Y.-L. Li, "An empirical study on performance evaluation of infrastructure investment of China based on DEA method from 2003 to 2007," Journal of Systems \& Management, vol. 18, no. 3, pp. 309-315, 2003 (Chinese).

[12] J. P. Yang and L. Gao, "DEA's CCR model for evaluation of urban infrastructure investment efficiency of Shaanxi Province," Applied Mechanics and Materials, vol. 685, pp. 424-428, 2014.

[13] G. Fancello, B. Uccheddu, and P. Fadda, "Data envelopment analysis (D.E.A.) for urban road system performance assessment," Procedia-Social and Behavioral Sciences, vol. 111, pp. 780-789, 2014.

[14] T. R. Sexton, R. H. Silkman, and A. J. Hogan, "Data envelopment analysis: critique and extension," in Measuring Efficiency: An Assessment of Data Envelopment Analysis, R. H. Silkman, Ed., vol. 32, pp. 73-105, Jossey-Bass, San Francisco, Calif, USA, 1986.

[15] J. Doyle and R. Green, "Efficiency and cross-efficiency in DEA: derivations, meanings and uses," The Journal of the Operational Research Society, vol. 45, no. 5, pp. 567-578, 1994. 
[16] Y. Sun, K.-Y. Wang, and X.-D. Yao, "Economic benefits evaluation of urban public infrastructure based on the DEA crossefficiency method," China Soft Science Magazine, vol. 1, pp. 172183, 2015 (Chinese).

[17] L. Liang, J. Wu, W. D. Cook, and J. Zhu, "The DEA game cross-efficiency model and its Nash equilibrium," Operations Research, vol. 56, no. 5, pp. 1278-1288, 2008.

[18] F. Yang, Q. Xia, and L. Liang, "DEA cross efficiency evaluation method for competitive and cooperative decision making units," System Engineering - Theory \& Practice, vol. 31, no. 1, pp. 92-98, 2011 (Chinese).

[19] J. Wu, L. Liang, and Y. Chen, "DEA game cross-efficiency approach to Olympic rankings," Omega, vol. 37, no. 4, pp. 909918, 2009.

[20] R. Ma, L. Yao, M. Jin, and P. Ren, "The DEA game crossefficiency model for supplier selection problem under competition," Applied Mathematics and Information Sciences, vol. 8, no. 2, pp. 811-818, 2014.

[21] C. Ma, D. Liu, Z. Zhou, W. Zhao, and W. Liu, "Game cross efficiency for systems with two-stage structures," Journal of Applied Mathematics, vol. 2014, Article ID 747596, 8 pages, 2014.

[22] Y.-Q. Liu, C. Zhou, and Y. Zhang, "Coordinate preference DEA method of software project risk assessment," in Proceedings of the International Conference on Communication Systems and Network Technologies (CSNT '12), pp. 675-678, Rajkot, India, May 2012.

[23] J. Du, W. D. Cook, L. Liang, and J. Zhu, "Fixed cost and resource allocation based on DEA cross-efficiency," European Journal of Operational Research, vol. 235, no. 1, pp. 206-214, 2014.

[24] H. Cheng, Y. Zhang, J. Cai, and W. Huang, "A Multiobjective programming method for ranking all units based on compensatory DEA model," Mathematical Problems in Engineering, vol. 2014, Article ID 807843, 14 pages, 2014. 


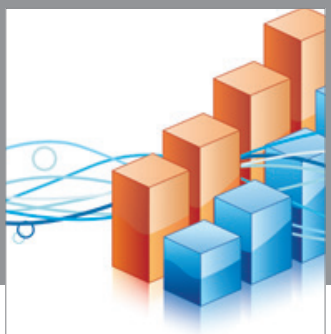

Advances in

Operations Research

vatem alat4

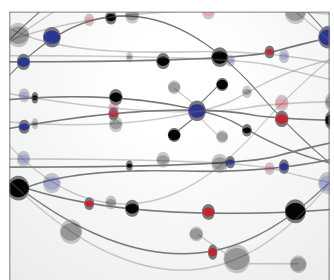

\section{The Scientific} World Journal
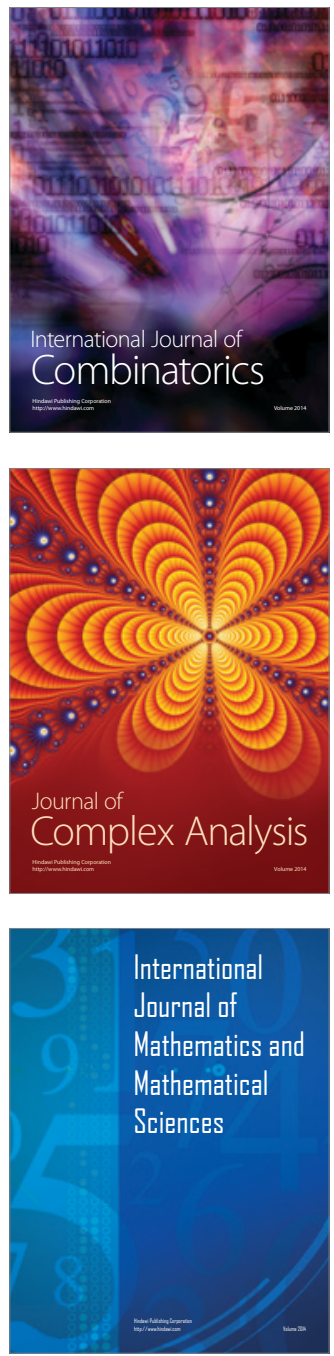
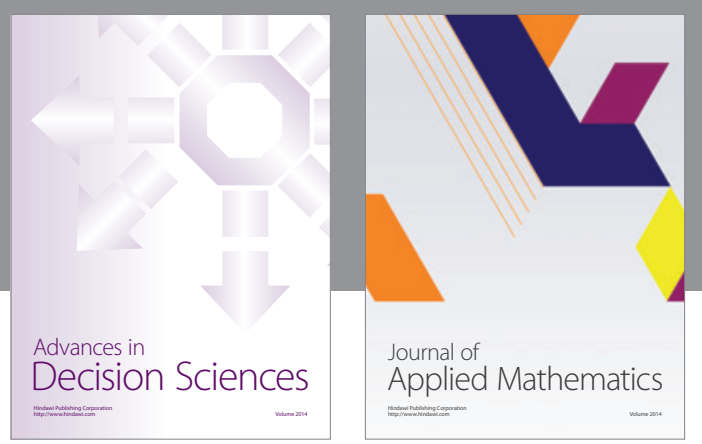

Algebra

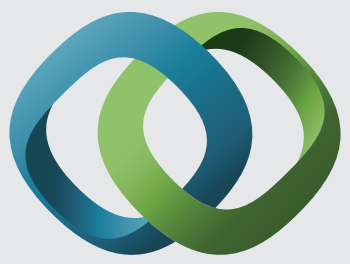

\section{Hindawi}

Submit your manuscripts at

http://www.hindawi.com
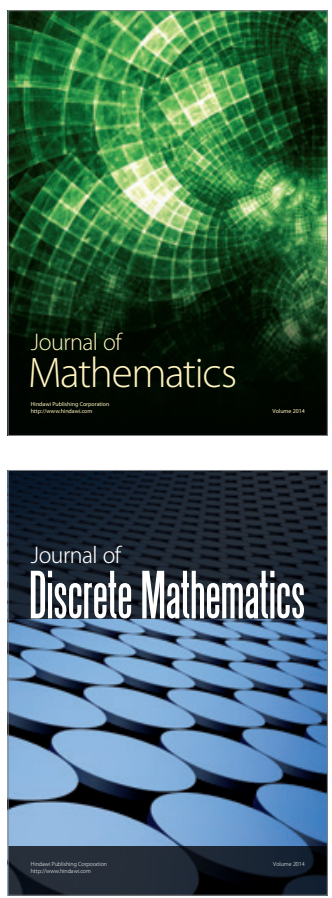

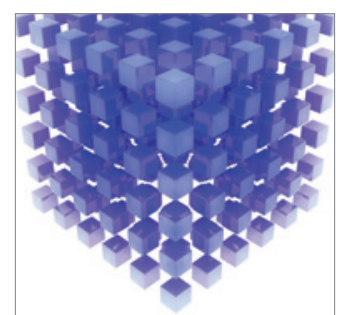

Mathematical Problems in Engineering
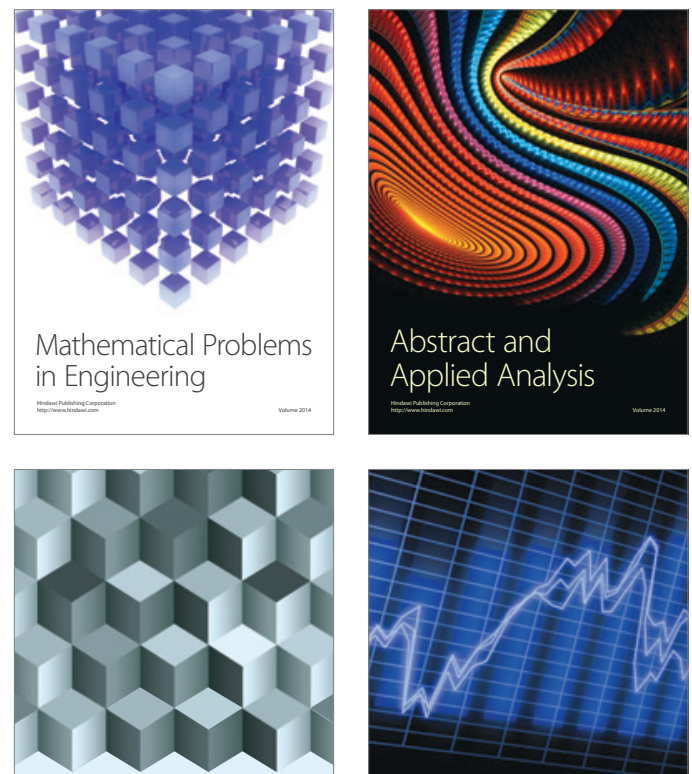

Journal of

Function Spaces

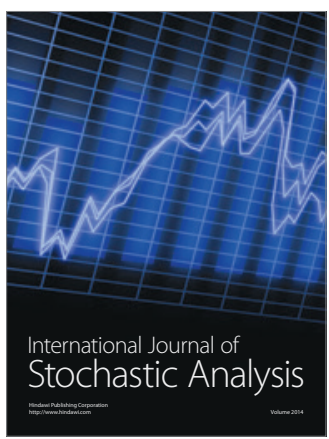

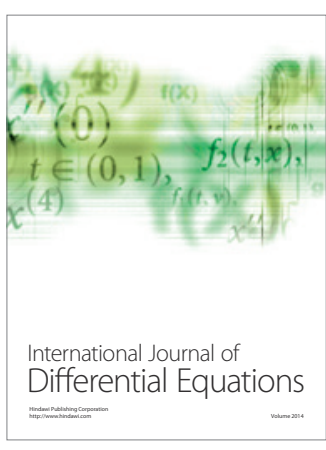
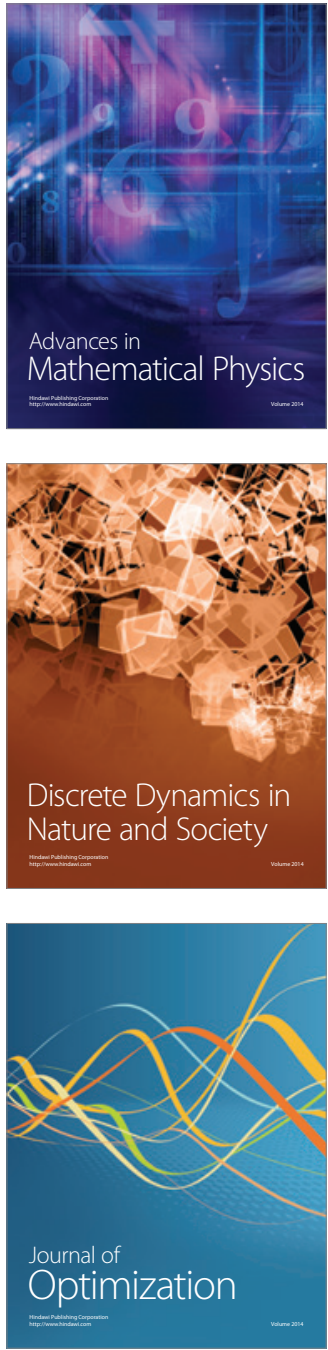